\title{
THE APPLICATION OF FERRATE FOR SEWAGE TREATMENT: PILOT- TO FULL-SCALE TRIALS
}

\author{
J-Q. JIANG ${ }^{1,2}$ \\ C. STANFORD ${ }^{3}$ \\ A. MOLLAZEINAL ${ }^{2}$
}

\author{
${ }^{1}$ School of Engineering and Built Environment, \\ Glasgow Caledonian University, \\ Cowcaddens Road, Glasgow, Scotland, G4 OBA, United Kingdom \\ ${ }^{2}$ Faculty of Engineering and Physical Science, \\ University of Surrey, \\ Guildford, Surrey GU2 7XH, United Kingdom \\ ${ }^{3}$ Wastewater Support Team (Process Development), \\ Southern Water Ltd., Falmer, East Sussex, BN1 9PY, United Kingdom
}

Received: 20/12/11

Accepted: 29/02/12 *to whom all correspondence should be addressed: e-mail: JiaQian.Jiang@gcu.ac.uk

\section{ABSTRACT}

This paper aims to study a relative new technology, the online generation and application of ferrate $(\mathrm{VI})$, for sewage treatment, from pilot to full scale trials at Hailsham North Wastewater Treatment Plant of Southern Water Ltd of UK. The work presented in this paper has significant impact on the use of ferrate $(\mathrm{VI})$ in water and waste water treatment practice; the online production and application of ferrate $(\mathrm{VI})$ resolves problems of the instability and needs no transportation. The current efficiency of ferrate $(\mathrm{VI})$ generation was up to $70 \%$ through the developed system, which is relatively high. For achieving the same phosphorus removal target from the crude sewage, the ferrate dose required was in a very lower range, $0.01-0.2 \mathrm{mg} \mathrm{Fe}{ }^{6+} / \mathrm{L}$ in comparison with high doses of ferric sulphate; these will reduce the chemical demand and sludge production and therefore result in a low operating cost and generate substantial cost saving in treating sewage.

KEYWORDS: Coagulation, online generation and application of ferrate( $\mathrm{VI})$, oxidation, precipitation, sewage treatment.

\section{INTRODUCTION}

The Water Framework Directives under European legislation require removing phosphorous $(P)$ /reducing its concentrations in sewage treatment in order to reduce the risk of eutrophication (Environment Agency, 2009). Chemical precipitation is one of common practices to remove $P$ as it enables to remove not only $\mathrm{P}$, but also COD, BOD and most colloidal matter. As a result of the chemical precipitation by either iron chloride or iron sulphate, the amount of residual iron in the final effluent is also controlled. It is in the interest of UK water companies to look for alternative iron supplies for $\mathrm{P}$ removal as it has predicted that in a few years in the UK, the price of iron salts would increase and their availability could be jeopardised in the future (O'Connell, 2005).

On the other hand, the superior performance of ferrate $(\mathrm{VI})$ as an oxidant/ disinfectant and coagulant in water and wastewater treatment has been reported (e.g., Jiang et al., 2001; Jiang et al., 2002; Fan et al., 2002; Ma and Lui, 2002; Sharma, 2002; Jiang, 2003; Jiang and Wang, 2003; Qu et al., 2003; Sharma, 2004; Jiang et al., 2005; 2006a,b; Jiang, 2007; Jiang et al., 2007; Sharma, 2007; Lee et al., 2009; Graham et al., 2010; Jiang et al., 2012). It has been shown that less ferrate iron doses are required to achieve the $P$ removal which is also an improvement on the treated wastewater and sludge quality (Jiang et al. 2006a). However, challenges have existed to the implementation of ferrate( $\mathrm{VI})$ technology in water and wastewater treatment practice. $\mathrm{Fe}(\mathrm{VI})$ solutions are generally unstable; their decomposition by reduction to $\mathrm{Fe}$ (III) species occurs rapidly at room temperature. The instability may be retarded but not stopped at low temperatures or with careful control of solution concentrations. Hence, without steps of refrigeration or high purification, the solutions cannot be 
stored for use in practice. Solid ferrate(VI) salts are stable, but they are costly as they require multiple purifications and long synthesis time. This makes it difficult to be used in industry. In order to solve the problems of instability and the high cost of using ferrate $(\mathrm{VI})$, it would be an ideal approach to generate ferrate in situ and apply the generated ferrate $(\mathrm{VI})$ directly for wastewater treatment (Jiang et al., 2009; Stanford et al., 2010).

This paper presents the results of applying online and electrochemically generated ferrate(VI) to treat domestic sewage, from pilot to full scale trials at Hailsham North Wastewater Treatment Plant of Southern Water Ltd of UK. The results compare the efficiency of ferrate(VI) vs. ferric irons in terms of the removal of $\mathrm{P}$, solids and organic matters.

\section{METHODS}

The pilot reactor system was the same as previously reported (Jiang et al., 2009). Briefly, it consists of two major components: 1) The ferrate(VI) production component includes the alkali tank; the chemical transfer pump; the electrochemical reactor; the power supply; the ferrate $(\mathrm{VI})$ product tank; the chemical dosing pump and the control box, and 2) The treatment part includes the submerged pump situated in the influent channel; hose; artificial channel where the ferrate was dosed and the exit hose that goes back to the main wastewater flow channel.

In order to carry out continuously full scale trials, from August 2010, the pilot reactor was upgraded to enable it to work automatically without any need to manually intervene. For this, several sensors were installed to control liquid levels in the raw material storage tank, in the reactor and the bund below the reactor. The control panel was modified to prevent any power from being delivered to the electrodes if the fluid level is too low and to stop pumping raw materials from the storage to the reactor if the level is too high. A time period controller was installed to limit the reactor to run 30 minutes and to reset ready for the next reaction cycle and the overflow control was modified. Finally, the system was upgraded to provide automatic control of the raw material transfer pump, reactor feed, reactor outlet valve, level controls within the day storage tank, and ferrate dosing rate from the day tank to the sewage channel.

The ferrate $(\mathrm{VI})$ production time was 30 min per each preparation. The resulting ferrate $(\mathrm{VI})$ was measured using an established spectroscopy method where the absorbance of the ferrate( $\mathrm{VI})$ solution was measured at $505 \mathrm{~nm}$ and the absorbance was converted to the concentration using an absorption coefficient of $1100 \mathrm{M}^{-1} \mathrm{~cm}^{-1}$. The ferrate $(\mathrm{VI})$ dosing flow rate was determined based on the desired dose and the ferrate $(\mathrm{VI})$ concentration measured. Samples after ferrate $(\mathrm{VI})$ dosing and mixing were collected and sent to Eurofins Laboratory of Southern Water for analysing concentrations of suspended solids (SS), chemical oxygen demand (COD), biochemical oxygen demand $(\mathrm{BOD})$, total phosphorus $(\mathrm{P}), \mathrm{pH}$ and residual Fe.

\section{RESULTS AND DISCUSSION}

\subsection{Pilot plant study}

The pilot plant's ferrate $(\mathrm{VI})$ production efficiency was studied for several batches using the previously established optimum current density, $36 \mathrm{~A} / \mathrm{m}^{2}$. Table 1 shows examples of the current efficiency of ferrate $(\mathrm{VI})$ generation with the resulting ferrate $(\mathrm{VI})$ concentrations, which were used to calculate the ferrate $(\mathrm{VI})$ dose volume. On average, the current efficiency was $43 \%$. An average energy consumption of $0.2 \mathrm{kWh}$ per gram of $\mathrm{Fe}^{6+}$ produced was observed (Table 1).

Table 1. The current efficiency of the pilot scale ferrate $(\mathrm{VI})$ production (electrolysis time was 25 min)

\begin{tabular}{lllll}
\hline $\begin{array}{l}\text { Activate } \\
\text { anode area } \\
\left(\mathrm{m}^{2}\right)\end{array}$ & $\begin{array}{l}\text { Applied } \\
\text { current } \\
(\mathrm{A})\end{array}$ & $\begin{array}{l}\text { Operating } \\
\text { voltage in } \\
\text { average }(\mathrm{V})\end{array}$ & $\begin{array}{l}\text { Current } \\
\text { efficiency } \\
(\%)\end{array}$ & $\begin{array}{l}\text { Specific energy } \\
\text { consumption } \\
\left(\mathrm{kWh} \mathrm{per} \mathrm{g} \mathrm{Fe}{ }^{6+}\right)\end{array}$ \\
\hline 0.43 & 15.5 & 29.5 & 42.7 & 0.20 \\
0.53 & 19.1 & 30.3 & 47.2 & 0.18 \\
0.23 & 8.4 & 28.3 & 38.6 & 0.21 \\
0.41 & 14.7 & 30.4 & $\underline{44.5}$ & $\underline{0.20}$ \\
\hline \multicolumn{7}{r}{} & Average & 43.0 & 0.20 \\
\hline
\end{tabular}


During the pilot plant study, properties of the crude sewage were tested. Concentrations of interested quality parameters varied from 242 to $730 \mathrm{mg} \mathrm{l}^{-1}$ for the suspended solids (SS), 523 to $1125 \mathrm{mg} \mathrm{l}^{-1}$ for the chemical oxygen demand (COD), 235 to $441 \mathrm{mg} \mathrm{I}^{-1}$ for the biochemical oxygen demand (BOD), and 11.3 to $18.5 \mathrm{mg} \mathrm{l}^{-1}$ for the phosphate as total $P$.

The comparative performance of ferrate $(\mathrm{VI})$ and ferric sulphate can be seen in Table 2 . With a low dose $\left(0.03 \mathrm{mg} \mathrm{Fe}^{-1}\right)$, ferrate $(\mathrm{VI})$ can achieve similar or better performance as a high dose of ferric sulphate $\left(37 \mathrm{mg} \mathrm{Fe}^{-1}\right)$.

Table 2. Comparative performance* of crude sewage treatment with ferric sulphate and Ferrate(VI)

\begin{tabular}{|c|c|c|c|c|}
\hline \multirow[t]{2}{*}{$\begin{array}{l}\text { Chemical and } \\
\text { dose }\end{array}$} & \multicolumn{4}{|c|}{$\begin{array}{l}\text { Average percentage removal for the given doses of given chemical } \\
\qquad(\%)\end{array}$} \\
\hline & SS & $P$ & COD & BOD \\
\hline $\begin{array}{l}\text { Ferrate }(\mathrm{VI}) \\
\left(0.03 \mathrm{mg} \mathrm{Fe} \mathrm{I}^{-1}\right)\end{array}$ & 79 & 56 & 50 & 30 \\
\hline $\begin{array}{l}\text { Ferric sulphate } \\
\left(37 \mathrm{mg} \mathrm{Fe}^{-1}\right)\end{array}$ & 78 & 59 & 54 & 43 \\
\hline
\end{tabular}

\subsection{Ferrate( $\mathrm{VI})$ production efficiency in full scale trials}

In order to achieve the highest current efficiency in full-scale trials, acid clean of anodes were conducted when the anodic passivation inhabited the current to pass through and therefore lowered the ferrate $(\mathrm{VI})$ production. The acid clean was done just before starting runs of the trials. For this purpose, $5 \%(\mathrm{w} / \mathrm{w})$ phosphoric acid was poured into the reactor and left overnight. Phosphoric acid is a weak acid which does not "attack" the electrodes but etches the steel surface only. After a contact time between 12 and $15 \mathrm{~h}$, the reactor was emptied and the electrodes checked. The current efficiency usually reaches above $60 \%$ after such cleaning.

Two adjustments were made before working on automatic running. First, the timers were used instead of using the level controller to control the transformation of raw chemical from the storage to the reactor and to keep discharge valve from reactor to storage tank open. Secondly, two stainless steel electrodes were used to replace a low level sensor in order to trigger a new batch running. The level sensor in the ferrate $(\mathrm{VI})$ storage tank stopped detecting a low level of ferrate $(\mathrm{VI})$ hence did not trigger a new batch. This was due to the sensor being inefficient as once the low level was detected, ferrate(VI) drops remained stuck on the sensor and prevented the return to the float position. As a result the sequences of signals would not operate correctly. Two stainless steel electrodes let an electrical current circulate from one to another. When the electrode is dry (low ferrate level), the current stops circulating and the new batch is triggered.

The modifications allowed the ferrate(VI) reactor operated automatically for continuous 24 hours runs. The ferrate $(\mathrm{VI})$ concentrations were measured regularly and are displayed in Figure 1 . As can be seen in Figure 1, the current efficiency decreased progressively from $60-65 \%$ to $35-45 \%$ as a resistant layer would form on the surface (ferric oxide and magnetite). Cleaning the electrodes by phosphoric acid enabled the current efficiency coming back up to $70 \%$ which is a very high performance for this kind of process. Corresponding to such high current efficiency, ferrate( $\mathrm{VI})$ concentration could reach to $538 \mathrm{mg} \mathrm{Fe}(\mathrm{VI})$ per litre, which is higher than that gained from the pilotscale production trials.

\subsection{The wastewater treatment performance by ferrate(VI) in full scale trials}

Through a preliminary trial, the ferrate $(\mathrm{VI})$ dose of $0.16 \mathrm{mg} \mathrm{Fe}^{6+} \mathrm{I}^{-1}$ was approved to be effective to reduce concentrations of $\mathrm{P}, \mathrm{COD}, \mathrm{BOD}$ and $\mathrm{SS}$ and thus this dose was used to run the full scale trials. Although the ferrate $(\mathrm{VI})$ production efficiency and the product concentrations varied, the constant dose was maintained by adjusting the ferrate (VI) dosing volume through a dose pump.

Figures 2- 5 show concentrations of $P, C O D, B O D$ and $S S$ from various samples during the period of 18 September 2010 - 5 October 2010 as well as the relevant percentage removals. For the above stated low dose $\left(0.16 \mathrm{mg} \mathrm{Fe}^{6+} \mathrm{I}^{-1}\right)$, ferrate $(\mathrm{VI})$ can achieve, in average removals, $64 \%$ of SS, $44 \%$ of phosphate, $46 \%$ of COD, and $40 \%$ of BOD when pH was above 9 . The comparative performance of 
ferrate(VI) and ferric sulphate shows that the ferrate(VI) dose of $0.16 \mathrm{mg} \mathrm{Fe}^{6+} \mathrm{I}^{-1}$ can achieve the similar performance as ferric sulphate could achieve at relatively a high dose $\left(25 \mathrm{mg} \mathrm{Fe}^{3+} \mathrm{I}^{-1}\right)$.

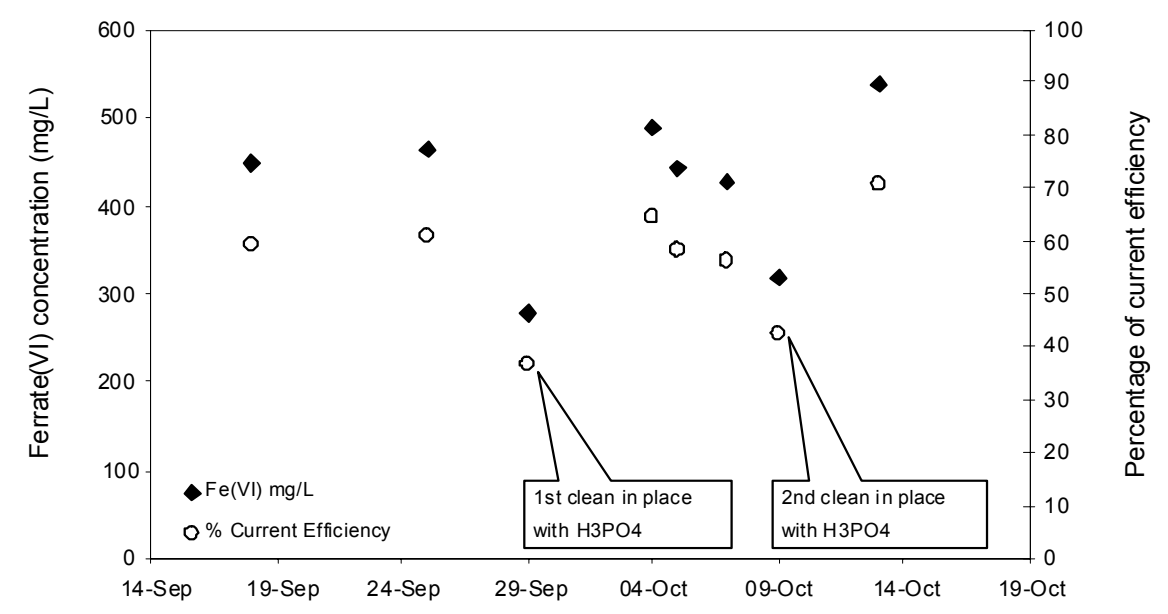

Figure 1. Ferrate concentration and current efficiency obtained with the ferrate

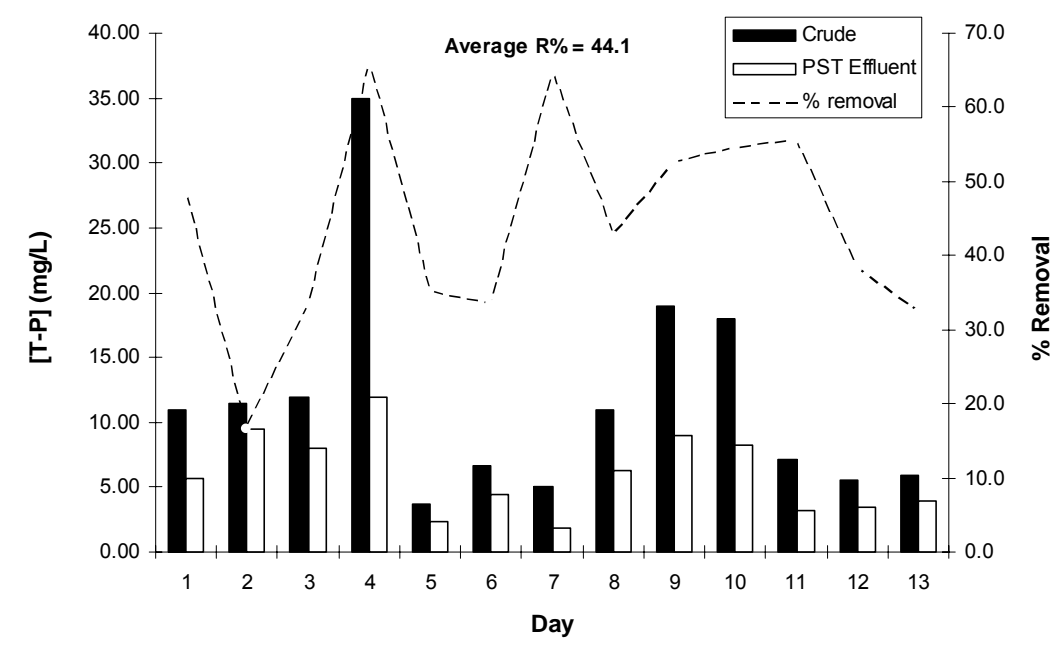

Figure 2. Total phosphorus concentration in crude sewage and the effluent after pre-sedimentation tank (PST) and percentage removals of $P$

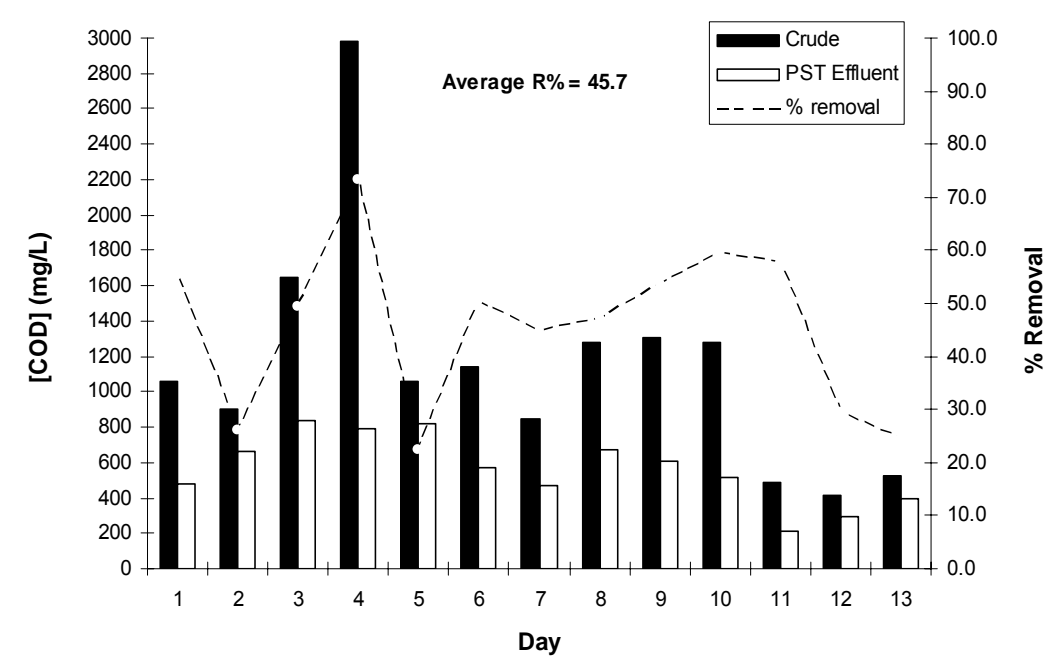

Figure 3. COD concentration in crude sewage and the effluent after pre-sedimentation tank (PST) and percentage removals of COD 


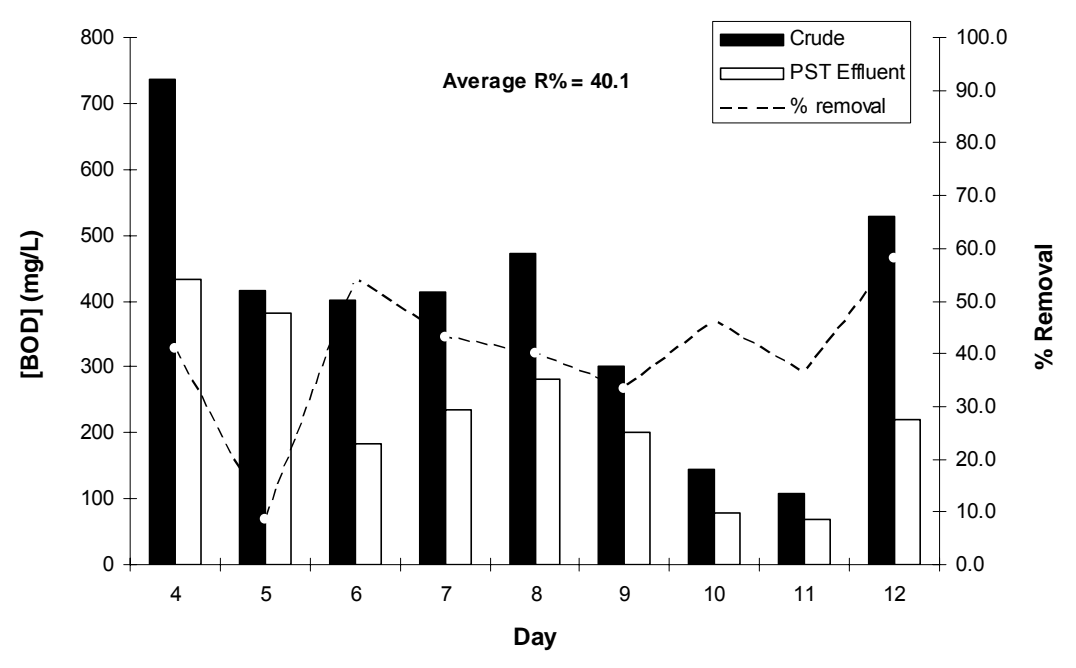

Figure 4. BOD concentration in crude sewage and the effluent after pre-sedimentation tank (PST) and percentage removals of $B O D$

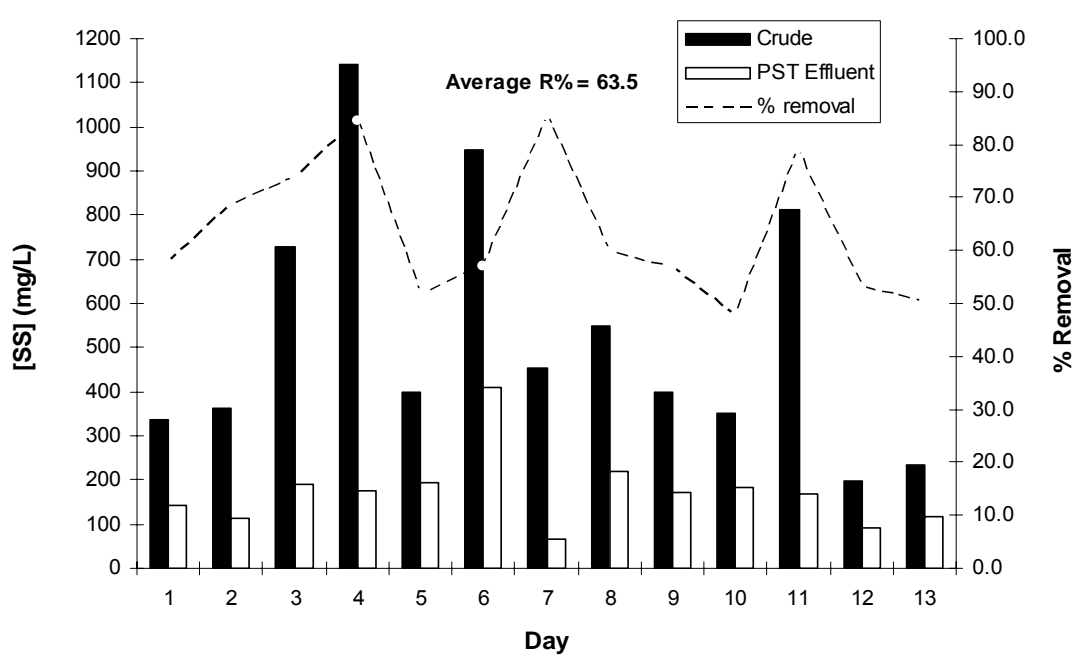

Figure 5. Suspended solids concentration in crude sewage and the effluent after pre-sedimentation tank (PST) and percentage removals of SS

\subsection{Discussion}

Both pilot- and full-scale trials showed that the dose of iron was approximately 100 times less when using $\mathrm{Fe}(\mathrm{VI})$ as compared to $\mathrm{Fe}(\mathrm{III})$ to achieve a similar sewage treatment performance. Such a large difference could be partly attributed to the high oxidation capacity of ferrate( $\mathrm{VI}$ ) (see Equations 1 and 2, Jiang et al., 2002).

$$
\begin{array}{ll}
\mathrm{FeO}_{4}{ }^{2-}+8 \mathrm{H}^{+}+3 \mathrm{e}^{-} \rightarrow \mathrm{Fe}^{3+}+4 \mathrm{H}_{2} \mathrm{O} & E^{0}=+2.20 \mathrm{~V} \\
\mathrm{FeO}_{4}{ }^{2-}+4 \mathrm{H}_{2} \mathrm{O}+3 \mathrm{e}^{-} \rightarrow \mathrm{Fe}(\mathrm{OH})_{3}+5 \mathrm{OH}^{-} & E^{0}=+0.72 \mathrm{~V}
\end{array}
$$

Therefore, very low doses of ferrate $(\mathrm{VI})$ can perform superior degradation on various organic matter and microorganisms, and this is evident of the equivalent COD and BOD removal in comparison with that achieved by ferric sulphate at high doses, this was observed in both pilot- and full scale trials. The outstanding performance in the reduction of COD with ferrate $(\mathrm{VI})$ is also consistent with previous studies, where, a range of organic contaminants have been shown to be readily oxidised by ferrate (VI) (Jiang, 2007).

High re-dox potential alone could not explain why ferrate( $\mathrm{VI})$ at a very low dose $(0.02 \mathrm{mg} / \mathrm{L}$ as $\mathrm{Fe})$ can achieve the similar removal efficiency as achieved by ferric sulphate at a high dose, e.g., 25 $\mathrm{mg} / \mathrm{L}$ as Fe. There must be other reasons behind such phenomena. First, oxidation by ferrate( $\mathrm{VI})$ could change the surface property of suspended solids and phosphate making them readily 
removable through coagulation and precipitation. Secondly, the byproducts of the ferrate(VI) oxidation are ferric ion or ferric hydroxide (see Equations 1 and 2) which are basic coagulant resources. Therefore, ferrate $(\mathrm{VI})$ can also perform coagulation after it degrades organic matter and microorganisms.

Another advantage of using online generated ferrate $(\mathrm{VI})$ is that very low dose of ferrate $(\mathrm{VI})$ generates much less volume and mass of the sludge in comparison with that from high dose of ferric salts. A previous study had demonstrated that even for the similar dose of ferrate(VI) and ferric(III), the sludge production from ferrate(VI) was less than that from ferric(III) (Jiang et al., 2006b). This is an extra benefit for the use of ferrate $(\mathrm{VI})$ in full scale wastewater treatment in terms of reducing the cost for sludge handling.

\section{CONCLUSIONS}

In the foregoing, the pilot- and full-scale trials demonstrated the feasibility of the online generation and application of ferrate $(\mathrm{VI})$ for sewage treatment. The current efficiency of the online ferrate $(\mathrm{VI})$ generation system was up to $70 \%$ under the study conditions, which is relatively high. For achieving the same phosphorus removal target from the crude sewage, the ferrate dose required was in a very lower range, $0.01-0.2 \mathrm{mg} \mathrm{Fe}{ }^{6+} / \mathrm{L}$ in comparison with high doses of ferric sulphate; these will reduce the chemical demand and sludge production and therefore generate substantial cost saving in treating sewage. Flow $\mathrm{pH}$ was crucial to achieve good treatment performance. Depending on individual circumstances, the ferrate $(\mathrm{VI})$ technology could be implemented in wastewater treatment practice. The technology has no ferrate $(\mathrm{VI})$ instability problem and needs no transportation, which promotes to use this technology in water and waste water treatment.

\section{REFERENCES}

Environment Agency in England (2009) URL: http://www.Environment-Agency.gov.uk, (assessed 10/05/2010).

Fan M.H., Brown R.C. and Huang C.P. (2002) Preliminary studies of the oxidation of arsenic(III) by potassium ferrate, Interl. J. Environ. Poll., 18(1), 91-96.

Graham N.J.D., Khoi T.T., Jiang J.Q. (2010) Oxidation and coagulation of humic substances by potassium ferrate, Water Sci. Technol., 62(4), 929-936.

Jiang J.Q., Lloyd B. and Grigore L. (2001) Disinfection and coagulation performance of potassium ferrate for potable water treatment, Environ. Eng. Sci., 18(5), 323-328.

Jiang J.Q., Lloyd B. (2002) Progress in the development and use of ferrate (vi) salt as an oxidant and coagulant for water and wastewater treatment, Water Res., 36, 1397-1408.

Jiang J.Q. (2003) Ferrate: a dual functional water treatment chemical, In: Proceedings of the 1st IWA Leading Edge Conference on Drinking Water and Wastewater Treatment Technologies, Noordwijk/Amsterdam, 26-28 May 2003.

Jiang J.Q. and Wang, S. (2003) Enhanced coagulation with potassium ferrate(VI) for removing humic substances, Environ. Eng. Sci., 20(6), 627-633.

Jiang J.Q., Yin Q., Zhou L.J. and Pearce P. (2005) Occurrence and treatment trails of endocrine disrupting chemicals (EDCs) in wastewaters, Chemosphere, 61, 244- 550.

Jiang J.Q., Wang S., Panagoulopoulos A. (2006a) The exploration of potassium ferrate(VI) as a disinfectant/coagulant in water and wastewater treatment, Chemosphere, 63(2), 212-219.

Jiang J.Q., Panagoulopoulos A., Bauer M. and Pearce P. (2006b) The application of potassium ferrate for sewage treatment, J. Environ. Managt., 79(2), 215-220.

Jiang J.Q., Wang S. and Panagoulopouls A. (2007) The role of potassium ferrate (VI) in inactivation of Escherichia coli and in the reduction of COD for water remediation, Desalination, 210, $266-273$.

Jiang J.Q. (2007) Research progress in the use of ferrate(VI) for the environmental remediation. J. Hazardous Mater., 146, 617-623.

Jiang J.Q., Stanford C., Alsheyab M. (2009) The online generation and application of ferrate(VI) for sewage treatment-A pilot scale trial, Separation and Purif. Technol., 68(2), 227-231.

Jiang J.Q., Zhou Z., Pahl O. (2012) Preliminary study of ciprofloxacin (cip) removal by potassium ferrate(VI), Separation and Purif. Technol., 88, 95-98. 
Lee Y., Zimmermann S.G., Kieu A.T., Von Gunten U. (2009) Ferrate (Fe(VI)) application for municipal wastewater treatment: a novel process for simultaneous micropollutant oxidation and phosphate removal, Environ. Sci. Technol., 43, 3831-3838.

Ma J., Liu W. (2002) Effectiveness of ferrate (VI) peroxidation in enhancing the coagulation of surface waters, Water Res., 36, 4959 -4962.

O'Connell D. (2005) Flocculant future, coagulant challenges, Speciality Chemicals Magazine, Jan.-Feb. 2005, 28-29.

Qu J.H., Liu H.J., Liu S.X. and Lei P.J. (2003) Reduction of fulvic acid in drinking water by ferrate, J. Environ. Eng.-ASCE, 129(1), 17-24.

Sharma V.K. (2002) Potassium ferrate (VI): an environmentally friendly oxidant, Advances in Environ. Res., 6,143-156

Sharma V.K. (2004) Use of iron (VI) and iron (V) in water and wastewater treatment, Water Sci. Technol., 49(4), $69-74$.

Sharma V. K. (2007) A review of disinfection performance of $\mathrm{Fe}(\mathrm{VI})$ in water and wastewater, Water Sci. Technol., 55, 225-230.

Stanford C., Jiang J.Q., Alsheyab M. (2010) Electrochemical production of ferrate (iron VI): application to the wastewater treatment on a laboratory scale and comparison with iron (III) coagulant, Water, Air, and Soil Poll., 209, 483-488. 